\title{
PROBLEMATISING UNFOCUSED WRITTEN FEEDBACK: A CASE STUDY ON FOUR UNIVERSITY STUDENTS' ESSAYS
}

\author{
Daron Benjamin Loo \\ Asia-Pacific International University \\ daronloo@apiu.edu
}

\begin{abstract}
In the past decade, many studies have sought to show the efficacy of different types of written feedback. All of these studies yielded consistent results, and at times contradicting results. Considering the nature of language teaching and learning, English language teaching (ELT) practitioners should consider problematising the issue of providing written feedback, instead of looking for a solution. Taking this into account, this study uses a case-study approach to evaluate the efficacy of unfocused feedback across multiple-drafts in an advanced English writing course taken by English majors at an international university in Thailand. Over a four-month semester, the class wrote five essays, with each essay having at least three drafts. In all drafts, unfocused feedback was provided with the assumption that students' prior English writing courses have helped them develop self-monitoring abilities. The data consist of the frequency of errors and unfocused feedback of the last three essays of four students. Subsequently, a correlation coefficient of the errors and unfocused feedback was calculated and results indicated that as the number of feedback decreased through drafts, the number of errors decreased as well. This shows a positive correlation between the two variables, albeit at varying degrees for different students. Students were also interviewed about their perceptions and expectations toward writing feedback. This study suggests that unfocused feedback may work for certain students, but not all.
\end{abstract}

Keywords: writing feedback, unfocused feedback, multiple-drafts

\section{Introduction}

The provision of written feedback, or corrective feedback, to students' writing tasks has been a point of discussion for many English language teaching (ELT) scholars and practitioners since Truscott's (1996) controversial claims (Bitchener, 2005; Bitchener, 2008; Chandler, 2003; Ellis, Sheen, Murakami, \& Takashima, 2008; Ferris \& Roberts, 2001; ; Sheen, Wright \& Modawa, 2009). These studies showed how students who received corrective feedback had improved in subsequent writing tasks or 
assessments. Many of these studies were conducted in English as a Second Language (ESL) writing classrooms, where students were still building their English language proficiency (Bitchener, 2008; Bitchener \& Knoch, 2009; Ellis, et al., 2008; Sheen, et al., 2009). An exception is Chandler's (2003) study where the sample consisted of first and second year University students majoring in music. To date, it appears that no study on written feedback has been carried out in a multilingual setting with advanced writing students, who have fulfilled English proficiency requirements for admission into a regular university program. Furthermore, no research has specifically studied university students majoring in English in an English as a Foreign Language (EFL) setting. Hence, this study aims to determine the relationship between the frequency of feedback and the frequency of errors. Specifically it aims to look at whether or not the gradual reduction of errors has a positive correlative relationship with the frequency of written corrective feedback. Before proceeding, it is crucial to point out that research concerning the efficacy of written feedback have been quite diverse (Ferris, 2004). A primary reason for this dissimilarity is that though they may look at similar types of written feedback, the research design employed is typically different. There are many factors at stake, such as the course objectives, the types of students, and the duration of the course. A reason for this diversity may be the belief that there is no universal solution to improve writers' writing skills, which calls for a problematisation of the issue (Hyland, 2012). In the following paragraphs, we will highlight the different types of course contexts, followed by an overview of the types of effects a type of writing feedback have on students' grammatical accuracy.

\section{Types of Writing Course in Studies on Written Feedback}

In a meta-analysis of corrective written feedback studies conducted in the late 1980s and early 1990s, Ferris (2004) found that all of the participants involved were students studying a foreign language at a basic level in an ESL context. Research in the past decade has recruited participants who are somewhat similar in nature, as seen in Table 1.

In terms of research design, perhaps ESL-type students are generally easier to recruit due to the broad objectives of the course. Generally, at an ESL-type writing course, students are expected to master writing mechanics - paying careful attention to grammatical accuracy. College courses, on the other hand, may focus on different types of genres and the development of content which are suitable to a specific course. Another point worth noting is that in all the studies listed in Table 1, different approaches were utilised to determine the efficacy of written feedback. 
Table 1

An overview of types of writing course in written feedback studies

\begin{tabular}{|c|c|c|}
\hline Study & $\begin{array}{l}\text { Number of } \\
\text { Subjects }\end{array}$ & Types of Writing Course \\
\hline $\begin{array}{l}\text { Ferris \& Roberts } \\
\text { (2001) }\end{array}$ & 72 & $\begin{array}{l}\text { Pre-freshman composition; grammar for } \\
\text { writers, U.S. University }\end{array}$ \\
\hline Chandler (2003) & 31 & $\begin{array}{l}\text { High intermediate/advanced reading } \\
\text { and writing class, U.S. College }\end{array}$ \\
\hline $\begin{array}{l}\text { Bitchener, et al. } \\
\text { (2005) }\end{array}$ & 53 & $\begin{array}{l}\text { Post intermediate ESOL migrant } \\
\text { learners, ESOL program }\end{array}$ \\
\hline Ellis, et al. (2008) & 49 & General English classes, Japan University \\
\hline Sheen, et al. (2009) & 80 & Intermediate ESL, U.S. College \\
\hline $\begin{array}{l}\text { Bitchener \& Knoch } \\
\text { (2010) }\end{array}$ & 63 & $\begin{array}{l}\text { Introductory Composition for } \\
\text { International students, U.S. University }\end{array}$ \\
\hline
\end{tabular}

\section{Types of Written Feedback}

Aside from the difference in types of courses, types of written feedback are quite diverse. In all these studies, these feedback types have been defined consistently (Ashwell, 2000; Bitchener, Young, \& Cameron, 2005; Ellis, et al., 2008), and there is a general consensus over how types of feedback are categorised. There are two main categories - each with a pair of constructs. First, there is the direct and indirect feedback pair. As its name suggests, direct feedback is any obvious supplication of correct forms (Bitchener \& Knoch, 2010; Ellis, et al., 2008). Correction could be provided directly above an error or on the margins of the essay. Direct feedback is argued to be helpful as it reduces confusion whilst revising, provides correct solutions to complex errors, offers explicit feedback on students' hypotheses, and is more immediate. Indirect feedback, on the other hand, is an indication that an error has been made without providing the correct form. Indirect feedback is commonly provided by underlining or circling the error, or writing in the margin the number of errors in a given line. When indirect feedback is given, writers are expected to figure out the correct form on their own. This encourages active reflection on existing knowledge and promotes noticing, which may subsequently lead to long-term acquisition (Bitchener \& Knoch, 2010). The second category of feedback is the focused and unfocused feedback pair. Focused feedback is selective in that the teacher, or the teacher and students, decide which types of errors to focus on. In providing focused feedback, only specific errors are treated while other errors are disregarded. Furthermore, as the class progresses through different types of writing assignments, the focus may shift from one type of error to another. On the contrary, unfocused feedback is extensive as it deals with different errors in a single piece of writing. When comparing the two, it is believed that focused feedback is more effective for beginner writers as their attention would be dedicated to several selected errors. It is suggested that focused feedback may encourage an overall improvement in structural and grammatical aspects of a written work (Ellis, et al., 2008). 
Aside from the pairs discussed previously, there are also other types of written feedback which are commonly used in the writing classroom. Teachers may opt to supplement their feedback with metalinguistic description. These metalinguistic descriptions, which could be in oral or written form, aim to explain reasons for an error, or to explain ways to rectify an error. In cases where direct feedback is provided, metalinguistic description is included to ensure that students are not merely copying the correct form in the revised draft (Bitchener, et. al. 2005; Bitchener, 2008; Bitchener \& Knoch, 2010). Subsequently, how corrective feedback is incorporated in revisions may be determined through the analysis of errors across a set of drafts (Ashwell, 2000; Chandler, 2003; Qi \& Lapkin, 2001).

\section{Effects of Different Types of Feedback}

Generally speaking, there seems to be positive outcomes for students who receive focused feedback, especially in terms of how long the correct form of a grammatical feature is maintained (Bitchener, et al., 2005; Bitchener, 2008; Ellis, et al., 2008, Sheen, et al., 2009). In the case of Sheen, et al., it was reported that students made improvement in other forms as well, aside from the focused forms. The expansion of improvement beyond the focus formed is attributed to the systematicity of how focused feedback is delivered. Furthermore, focused feedback seems to have a lasting positive effect, in that improvement was retained after employing a post-test or a delayed post-test (Bitchener, 2008; Ellis, et al., 2008). A point for consideration, though, is that focused feedback, or any type of feedback for that matter, may not have a desired positive impact on errors as student-writers may only be copying the correct form, especially if the correct form is given directly. This perhaps stems from the claim that different grammatical features occupy different cognitive domains. Hence the method for treatment may vary (Bitchener, et al., 2005). Aside from focused feedback, research that employed direct feedback also showed writing improvement in subsequent drafts (Bitchener \& Knoch, 2010). Interestingly, studies which employed unfocused feedback showed that though there were no significant grammatical accuracy gains, as compared to students who received focused feedback, there was still a slight improvement. As seen in Ellis et al.'s (2008) study, students who received unfocused feedback did improve and made minimal errors in subsequent drafts. Nevertheless, the lack of improvement among students who received unfocused feedback may be attributed to the plethora of errors student writers need to attend to (Bitchener, 2008; Sheen, et al., 2009), as opposed to students who focus only on a type of grammatical feature.

These positive results need to be carefully interpreted, though. Accuracy gains in these studies do not mean that an overall improvement has occurred over a longitudinal period. The improvement mentioned in most of these studies are concerned only with targeted forms (Bitchener, et al., 2005; Guénette, 2007), instead of an overall improvement for different grammatical and structural forms. In addition, the improvement made in one writing assignment may not necessarily transfer to a new writing topic (Bitchener, et al., 2005; Chandler, 2003). Moreover, improvements made may be due to student writers mindlessly revising errors without much thought. Hence, correct forms are not acquired. Student writers may 
also avoid using grammatical features which they find problematic in future essays (Truscott, 2007).

Another aspect which may influence the interpretation of results is the research design. Many of the research designs of the studies in writing corrective feedback have been quite inconsistent, which renders them incomparable. In all these studies, features invariably differ, such as types of participant, types of writing, research context, grammatical feature treated, types of feedback, duration of research (Ferris, 2004). To parallel the notion that language use is contextually bound, it has been proposed that practitioners in the field of applied linguistics should focus more on problematizing the issue, instead of proposing solutions (Hyland, 2012). Taking note of the need to examine how written feedback affects advanced English majors, and the dissimilar nature of writing students and classes, as well as the proposal to problematize written feedback, this study will use a case study approach to determine the efficacy of unfocused feedback by looking at correlative links between unfocused feedback and writing errors across multiple drafts provided to third-year university subjects majoring in English who were enrolled in an advanced writing course. Unfocused feedback is selected because of its proposed suitability for more advanced students, where they are assumed to be more independent and aware of their writing skills.

\section{Research Design and Sample}

To problematise unfocused feedback, this study will employ a case study approach. A case study approach is chosen because of the individualised effects written feedback may have on each student (Ferris, 2004). The reason why students are treated as individual case studies is due to the possibility of students reacting differently to the type of feedback provided.

The sample of this study consists of four students who were enrolled in an advanced composition course. The students are all English majors, studying different areas of emphasis, namely Teaching English to Speakers of Other Languages (TESOL) and English for Communication. Three case subjects, Beau, Vicky, and Kenny received unfocused feedback in their essays while the fourth, Dina, did not receive any unfocused feedback, except for an occasional oral or written comment (all names are pseudonyms). In other words, Dina was the control subject case for this study. Since Dina is a communications major, she has taken more writing courses prior to this course. For all the case subjects, the amount of unfocused feedback was compared to the number of errors and the correlation coefficient values were calculated. Furthermore, the frequency of types of errors was calculated across three drafts of a topic for each subject and was validated by an inter-rater. Each case subject was also interviewed.

Since this is an advanced composition course, students have taken other composition classes, either as a prerequisite for this particular course, or as a graduation requirement. It is then assumed that students would have a certain level of familiarity with the type of feedback employed in this study. Students, being in their third year, were also expected to be able to independently self-monitor their own writing. The class met twice a week for a total of four hours per week, over a 
period of thirteen weeks. All of the essays were narratives, but addressing different topics. The teaching procedure began with an introduction of a new topic (humour, anger, memorable experience, culture, language), followed by a brainstorming session by students. Next, students write up and submit the drafts (up to three). The researcher-teacher returned the drafts within two to three days. The returned drafts contained unfocused feedback. Errors were either circled or underlined, and were not extensive. This meant that not all errors were indicated. In a few cases, direct correction is given. These instances were typically confined to word-choice errors. A new draft was submitted in the next class, and a review of errors made by students was discussed as a class activity. Students were also engaged in peer revision and self-editing. For this study, the last three essays were selected for analysis. These three essays were written over the span of six weeks, with each essay having at least three drafts. Hence, the data of this study was made up of 36 pieces of writing by four different writers. The topics are memorable experience, personal culture, and English language learning experience.

\section{Results}

As this study's focus is to see the relationship of errors and feedback for individual students, a within-case approach was utilised. Hence, each student's draft was compared with his or her own subsequent drafts. To see whether the frequency of written feedback affected the frequency of errors, correlation coefficient between errors and written feedback was calculated. The purpose of this calculation is to analyse the strength of relationship between the frequency of errors and the frequency of feedback. Note, though, that an analysis of correlation does not equate a causal relationship. Furthermore, the increase or decrease on the frequency of errors may be due to other confounding variables beyond the control of the researcher. Table 2 shows the frequency of errors and feedback for each student, while Figure 1 shows the linear regression for each of the experimental students.

Table 2

Frequency of errors and unfocused written feedback (UWF) for Beau, Kenny, and Vicky

\begin{tabular}{ccccccc}
$\begin{array}{c}\text { Beau } \\
\text { Draft }\end{array}$ & \multicolumn{2}{c}{$\begin{array}{c}\text { Memorable } \\
\text { Experience }\end{array}$} & \multicolumn{2}{c}{ Personal Culture } & \multicolumn{2}{c}{$\begin{array}{c}\text { English Language } \\
\text { Learning Experience }\end{array}$} \\
\cline { 2 - 7 } & Errors & UWF & Errors & UWF & Errors & UWF \\
\hline 1 & 45 & 8 & 81 & 49 & 29 & 22 \\
2 & 38 & 6 & 38 & 9 & 12 & 8 \\
3 & 24 & 3 & 32 & 2 & 6 & 6 \\
\hline
\end{tabular}




\begin{tabular}{|c|c|c|c|c|c|c|}
\hline \multicolumn{7}{|l|}{ Kenny } \\
\hline \multirow[t]{2}{*}{ Draft } & \multicolumn{2}{|c|}{$\begin{array}{l}\text { Memorable } \\
\text { Experience }\end{array}$} & \multicolumn{2}{|c|}{ Personal Culture } & \multicolumn{2}{|c|}{$\begin{array}{l}\text { English Language } \\
\text { Learning Experience }\end{array}$} \\
\hline & Errors & UWF & Errors & UWF & Errors & UWF \\
\hline 1 & 40 & 11 & 42 & 32 & 59 & 37 \\
\hline 2 & 48 & 5 & 65 & 28 & 97 & 77 \\
\hline 3 & 121 & 28 & 41 & 3 & 41 & 8 \\
\hline \multicolumn{7}{|l|}{ Vicky } \\
\hline \multirow[t]{2}{*}{ Draft } & \multicolumn{2}{|c|}{$\begin{array}{l}\text { Memorable } \\
\text { Experience }\end{array}$} & \multicolumn{2}{|c|}{ Personal Culture } & \multicolumn{2}{|c|}{$\begin{array}{l}\text { English Language } \\
\text { Learning Experience }\end{array}$} \\
\hline & Errors & UWF & Errors & UWF & Errors & UWF \\
\hline 1 & 54 & 13 & 47 & 20 & 43 & 28 \\
\hline 2 & 49 & 4 & 54 & 12 & 36 & 4 \\
\hline 3 & 66 & 18 & 40 & 3 & 26 & 4 \\
\hline
\end{tabular}

It appears that in most cases, there seems to be a reduction in errors in subsequent drafts. This is observable in the calculation of correlation coefficient as well. In the order of correlative strength, Beau ranked the strongest (0.77), followed by Kenny (0.60), and finally Vicky (0.43). Figure 1 illustrates the scatter plot of the frequency of unfocused feedback and errors, with linear regression lines drawn across the plots. As observed, all subjects show a positive correlation, albeit at varying degrees of strength. The different dots represent the essays written by the three experiment case subjects.

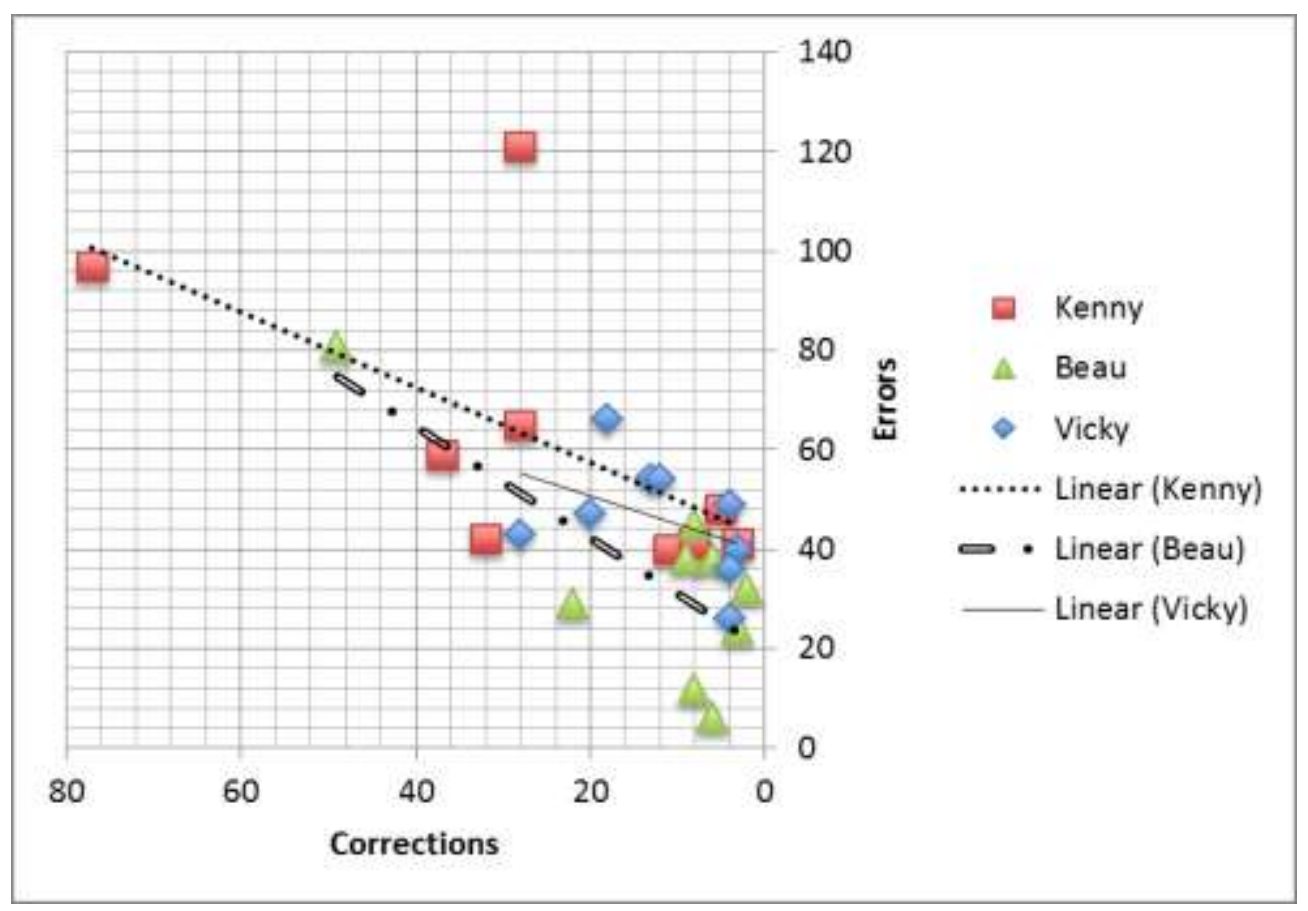

Figure 1. Scatter plot of frequency of feedback and errors with linear regression 


\section{Kenny}

Kenny was one of the three subjects who received unfocused feedback. Prior to entering university, Kenny had undergone a year of remedial English as he did not have any substantial English education in high school. In Kenny's interview, he mentioned that he had expected a writing teacher to provide focused feedback, especially on ideas and organisation. Nonetheless, in his English writing classroom experience, his teachers had always given unfocused feedback. Furthermore, Kenny thought that direct feedback would facilitate revision, as well as acquisition of correct forms. Despite these comments, Kenny's work showed improvement even without direct feedback. In terms of writing accuracy, Kenny struggled with verbs (tense, subject-verb agreement). Nonetheless, the instances of errors decreased across multiple drafts. For instance, in his narrative on language learning experience, Kenny's percentage of verb errors was reduced from $33 \%$ in the first draft to $22 \%$ in the final draft.

\section{Beau}

Of all the three subjects who received unfocused feedback, Beau's result showed the strongest correlation between the amount of feedback and the number of errors. This may be due to Beau's writing experience in high school. In high school, Beau's English classes had creative writing assignments. The type of feedback given in his classes was generally metalinguistic descriptions. With regards to unfocused feedback, Beau thinks it may be detrimental as students may not be able to cope with an array of different types of errors. Beau suggests that indirect unfocused feedback may be beneficial for advanced students.

Nonetheless, Beau, being a TESOL major, also acknowledges that teachers may not have enough time to provide feedback for every mistake. With regards to writing accuracy, Beau made fewer errors than the three other students. Even so, Beau demonstrated a reduction in errors throughout three drafts. For instance, Beau's misuse of articles (definite and indefinite article) was reduced from $40 \%$ in the first draft to $25 \%$ in the final draft.

\section{Vicky}

Vicky, on the other hand, showed a rather weak correlation between feedback and errors. This could perhaps be due to Vicky's perception towards unfocused feedback. Vicky's previous writing experience saw only an emphasis on content and organisation, and not so much on grammar. Vicky also mentioned that the way in which feedback is provided, and not the frequency of feedback, is important. This belief is grounded in the notion that it will help her become more aware of what she needs to improve. Moreover, Vicky points out that feedback needs to be appropriate to the proficiency level of a learner. Vicky suggests that minimal intervention from teachers is acceptable for more advanced writers. Similar to Kenny, Vicky struggled with the usage of verbs. In her essay on language learning 
experience, Vicky's errors in verb usage amounted to $53 \%$. However, this was reduced in the last essay, with only $22 \%$ errors.

\section{Dina}

Unlike the other three subjects, Dina did not receive any unfocused feedback, aside from an occasional oral or written comment at the end of each essay. Since Dina was a communication student, she had had the most writing courses. Hence, it was expected that she would be familiar with different feedback conventions. Dina comes from an international school which had English as its medium of instruction. Nonetheless, not much emphasis was placed on writing. Prior to entering university, Dina had to take a remedial English course. Similar to Vicky and Kenny, Dina struggled a lot with verbs. In her first draft of her language learning experience essay, Dina's errors in verbs amounted to $60 \%$. Dina also struggled with nouns (form, wrong noun choice), with $44 \%$ errors. These percentages of errors were reduced, though, in the final draft, with $13 \%$ for the former and $22 \%$ for the latter.

\section{What Then Should Writing Teachers Do?}

When looking at each student's overall progress over nine drafts, it appears that unfocused feedback may have had a positive bearing on the reduction of errors. Even though the case subjects are dealing with various errors, they seem to be able to remedy these in subsequent drafts. This supports the notion that advanced students may have the necessarily skills to self-correct (Bitchener \& Knoch, 2010; Chandler, 2003). Aside from student's ability to self-correct, the frequency of feedback may also encourage improvement. There was a gradual decrease in the amount of feedback across drafts, yet this did not deter each case subject's improvement. This may stem from a sense of accountability that advanced writing students have for their own writing.

Another issue worth mentioning is that subjects in this study showed grammatical accuracy gains over several forms, instead of a target or focused form. Throughout the semester, the researcher-teacher constantly reminded the students that they must also rely on themselves for feedback. Furthermore, the sample engaged in peer-review and worked on grammatical exercises built based on their written work, as suggested by Ferris (2004). Perhaps these, plus in addition to/together with their experience in previous writing courses, as well as incorporating multiple-drafts in writing courses have encouraged an awareness of their writing capabilities and the ability to notice struggles they may have (Bitchener \& Knoch, 2010). On the contrary, even though each case subject seems to show that there is a linear progression of improvement across drafts, it may not be reflected when the student-writer starts a new topic. This may stem from the oversight of transferal of learned corrections from a previous topic. This may further support the notion that students, at least within the parameters of this study, did not fully acquire the correct forms. Furthermore, there are instances in later drafts where an error is greatly reduced. This may be due to the correct application of a grammatical feature, or it could also be an avoidance strategy as well (Truscott, 2007). 
What this study has shown is the further problematisation of written feedback. Like its counterpart, unfocused feedback has been shown to have some level of positive relationship to the reduction of errors. This result should not be taken at face value, though, as there are many confounding variables which may have affected its efficacy either positively or negatively. Nonetheless, what does this say about other studies on written feedback then? For one, it does not refute the validity of other studies as the research design of this particular study is essentially different from that of others. Another point is that a within-case approach may give a more in-depth view of how each student is performing across multiple topics and multiple drafts, which other studies may have missed. Taking an ethnomethodology stance when investigating what works best for our students allows teachers to cater to the diverse needs of each student. In addition, this study supports the notion that in the field of ELT, we need to be eclectic and accept that methods or approaches are not universally applicable to all students. As seen in the data, unfocused feedback may have not worked best with Vicky. With this kind of information, teachers could explore other feedback alternatives which may be more effective. This exploration can also involve students' input, where students can work with their teachers in understanding which type of written feedback may work best. Even so, it should be understood that grammatical accuracy is not the only goal in a writing course. Writing teachers should strive for a broader objective, which is to help students to develop as better communicators. This can be done through helping students become more confident and independent in using a language which may be foreign to them (Mori, 2011).

\section{Implications and Limitations}

Unfocused feedback may cast the teacher as being thoughtless in giving feedback from the students' perspective. The results of these case studies, however, show that unfocused feedback can be helpful. Nonetheless, as seen in each case study, the case subjects have beliefs about unfocused feedback. This may provide support for the notion that feedback affects students differently. Another issue found from the interviews is that all the case subjects believed in the necessity of feedback. Hence, the possible exclusion of feedback needs to be dealt with carefully. Perhaps more advanced students are capable of a complete reliance on self in improving their writing. In terms of its limitations, this study was only conducted over six writing assignments, hence it may not suffice for any longitudinal generalisations. Furthermore, this study only looked at errors at the grammatical level, with the rare occasion of word choice errors. Writing, as we know, involves more than just grammatical accuracy, but also cohesion and organisation. A future direction with regards to unfocused feedback could be to analyse the effects of this type of feedback on the reduction of incorrect use of different parts of speech.

\section{Conclusion}

This study took a case study approach to look at how individual student-writers reacted to unfocused feedback. Results of this study found that in most cases, there 
seems to be a positive relationship between the reductions of errors with the frequency of feedback. Though seemingly positive, the results of this study, like other studies in written feedback, must be taken cautiously. However, this study could perhaps add to the pool of evidence that supports the idea that written feedback is indeed valuable, and it could instigate a reconsideration for Truscott's claims that feedback is ineffective and useless. An important take away for this study though, is a call for teachers to strive for a better understanding of how each student learns for an optimal teaching and learning environment. As Ferris (2004) mentioned, writers are essentially different from one another, which means how they react to a feedback may differ as well (Bitchener, 2005).

\section{References}

Ashwell, T. (2000). Patterns of teacher response to student writing in a multipledraft composition classroom: is content feedback followed by form feedback the best method? Journal of Second Language Writing, 9(3), 227-257.

Bitchener, J. (2008). Evidence in support of written corrective feedback. Journal of Second Language Writing, 17, 102-118.

Bitchener, J., \& Knoch, U. (2009). The relative effectiveness of different types of direct written corrective feedback. System, 37, 322-329.

Bitchener, J., \& Knoch, U. (2010). Raising the linguistic accuracy level of advanced L2 writers with written corrective feedback. Journal of Second Language Writing, 19, 207-217.

Bitchener, J., Young, S., \& Cameron, D. (2005). The effect of different types of corrective feedback on ESL student writing. Journal of Second Language Writing, 14, 191-205.

Chandler, J. (2003). The efficacy of various kinds of error feedback for improvement in the accuracy and fluency of $L 2$ student writing. Journal of Second Language Writing, 12, 267-296.

Ellis, R., Sheen, Y., Murakami, M., \& Takashima, H. (2008). The effects of focused and unfocused written corrective feedback in an English as a foreign language context. System, 36, 353-371.

Ferris, D., \& Roberts, B. (2001). Error feedback in L2 writing classes: How explicit does it need to be? Journal of Second Language Writing, 10, 161-184.

Ferris, D. R. (2004). The "grammar correction" debate in L2 writing: where are we, and where do we go from here? (and what do we do in the meantime ...?). Journal of Second Language Writing, 13, 49-62.

Guénette, D. (2007). Is feedback pedagogically correct? Research design issues in studies of feedback on writing. Journal of Second Language Writing, 16, 40-53.

Hyland, K. (2012). Disciplinary identities. United Kingdom: Cambridge University Press.

Mori, R. (2011). Teacher cognition in corrective feedback in Japan. System, 39, 451467.

Qi, D. S. \& Lapkin, S. (2001). Exploring the role of noticing in a three-stage second language writing task. Journal of Second Language Writing, 10, 277-303. 
Sheen, Y, Wright, D.,\& Modawa, A. (2009). Differential effects of focused and unfocused written correction on the accurate use of grammatical forms by adult ESL learners. System, 37, 556-569.

Truscott, J. (1996). The case against grammar correction in L2 writing classes. Language Learning, 46, 327-369.

Truscott, J. (2007). The effect of error correction on learners' ability to write accurately. Journal of Second Language Writing, 16, 255-272. 